\title{
FINITE ELEMENT ANALYSIS OF SADDLE SUPPORT FOR STACK HEAT EXCHANGER
}

\author{
Jaydip Gundu Patil \\ Department of Mechanical Engineering \\ Rajarambapu Institute of Technology, \\ Islampur, India \\ Nilesh More \\ Mechanical Design Engineer, \\ Geecy Engineering Pvt. Ltd. \\ Mahape, Navi Mumbai
}

\begin{abstract}
Process equipment is a leak proof container designed to hold or carry the gas or liquid or solid at a substantially high pressure. Examples of common process equipment utilized within the petroleum refining and chemical processing industries are storage tanks, boilers, pressure vessels and heat exchangers. Stack heat exchanger is a device in which arrangement of two or three horizontal heat exchangers placed one above other. During this paper, the horizontally stacked shell and tube heat exchanger supported on saddles is analyzed. The finite element analysis for various configurations of saddle supports is completed using ANSYS. The stress intensities in various cases are analyzed and also the optimal stresses in saddle with the loading condition is taken into account as the most suitable design for the stack heat exchanger. The reduction in stress intensity is found for one amongst the cases.
\end{abstract}

Keywords- Process Equipment, Heat Exchanger, Stack, Saddle, Analysis

\section{INTRODUCTION}

Process equipment is employed to carry gas or liquid or solid at a substantially high pressure that is usually different from the ambient pressure for storage purpose or processing purpose. In general, process equipment is utilized to store and transmit the liquid, solid, vapour and gases under pressure. Examples of common process equipment utilized in the petroleum refining and chemical processing industries include, but are not limited to, storage tanks, boilers and heat exchangers [1].

Stack heat exchanger are the arrangement of two or three horizontal heat exchangers placed one above other. Exchangers are stacked because of several aspects like process requirement, structural constraint, process plant requirement etc. Two exchangers series or parallel are usually stacked. [11] Two exchangers in dissimilar services can even be stacked. Sufficient clearance must be provided for shell and channel side piping between the 2 exchangers.

\author{
Dr. Samir B. Kumbhar \\ Department of Mechanical Engineering \\ Rajarambapu Institute of Technology, \\ Islampur, India \\ Ranjit A. Patil \\ Department of Mechanical Engineering \\ Rajarambapu Institute of Technology, \\ Islampur, India
}

For the horizontal heat exchanger saddle is used as a support of the equipment and are welded or permanently fixed to the exchanger. The suitable design of saddle support is most significant factor for stresses developed in exchanger. If the design of saddle support isn't correct it will end in higher stresses at exchanger junction and can result in failure of heat exchanger [2]. Therefore, the design of saddle support and determining the stresses developed in saddle and part of heat exchanger is a very important step during design of a heat exchanger. The forces applied on saddle support because of the weight of heat exchanger and internal pressure, causes stresses within the saddle supports [3-5].

In this paper, analysis of different saddle designs is carried out using ANSYS 19.1 software for stack heat exchanger. Von-mises stresses is evaluated for all four saddle designs in ANSYS and compared these stresses with each other for determining the optimal saddle design [6-10].

\section{PROPOSED SYSTEM}

a) Collection of different design models of top exchanger support

1. Saddle models for top exchanger

The different design model collections of saddle for top exchanger using CATIA are,

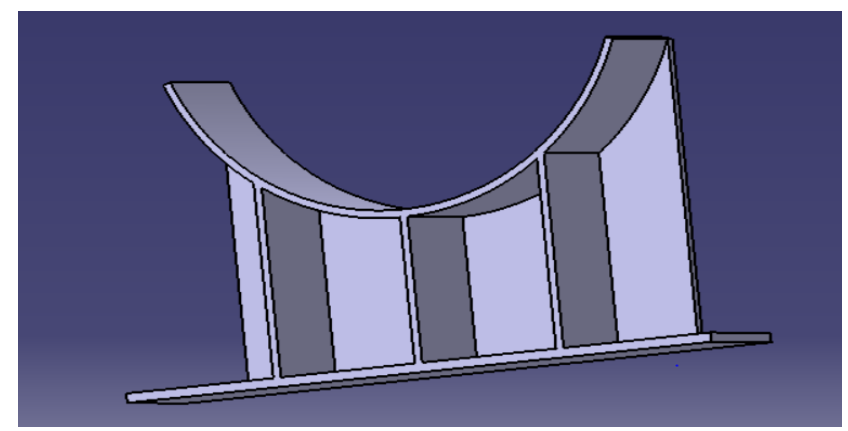




\section{International Journal of Engineering Applied Sciences and Technology, 2020 \\ Vol. 5, Issue 5, ISSN No. 2455-2143, Pages 78-85 \\ Published Online September 2020 in IJEAST (http://www.ijeast.com)}

Fig.1.1-3D Model of Design 1

Fig.1.1: Shows Design collection of saddle with three ribs and web plate with rear side location. The ribs are placed at a specific distance from the center rib plate.

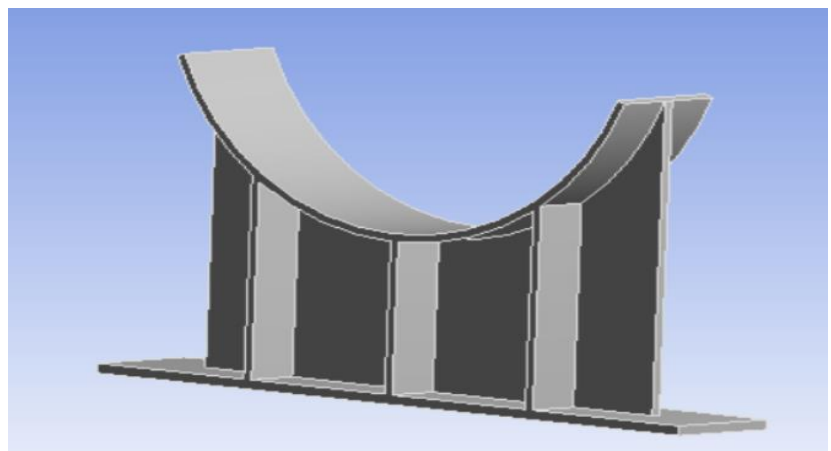

Fig.1.2-3D Model of Design 2

Fig.1.2: Shows Design collection of saddle with three ribs and web plate with center location. The ribs are placed at a specific distance from the center rib plate.

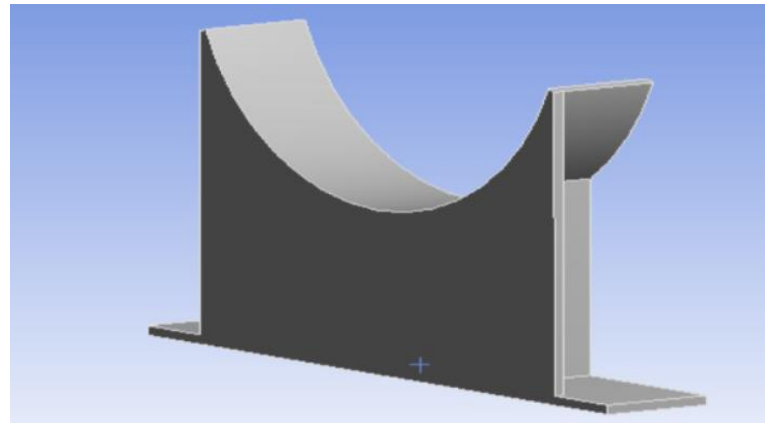

Fig.1.3-3D Model of Design 3

Fig.3.3: Shows Design collection of saddle with three ribs and web plate with front side location. The ribs are placed at a specific distance from the center rib plate.

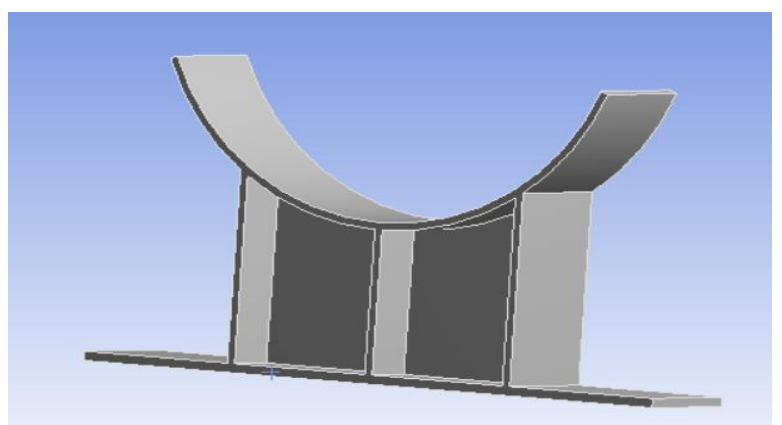

Fig.1.4-3D Model of Design 4
Fig.3.4: Shows Design collection of saddle with three ribs and web plate with center location and between ribs only. The ribs are placed at a specific distance from the center rib plate.

\section{FEA mesh model's}

The following Fig.3.5 to Fig.3.8 shows various design model collection of saddle i.e. Design 1 to Design 4 model meshing,

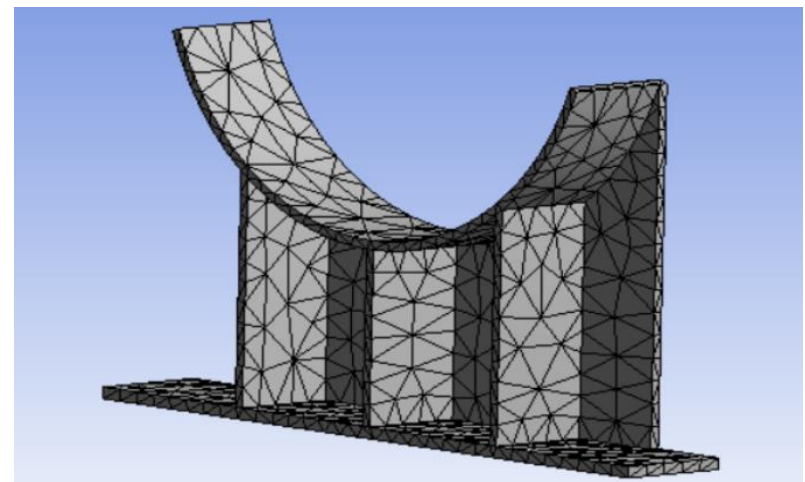

Fig.2.1: Mesh Model of saddle of design 1

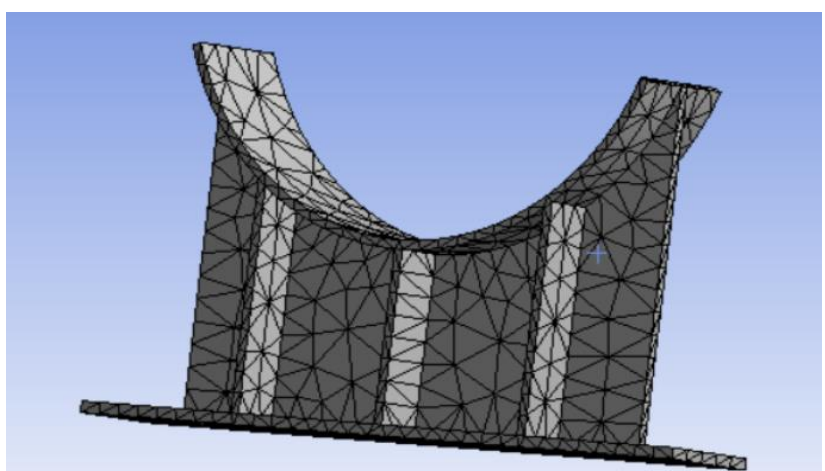

Fig.2.2: Mesh Model of saddle of design 2

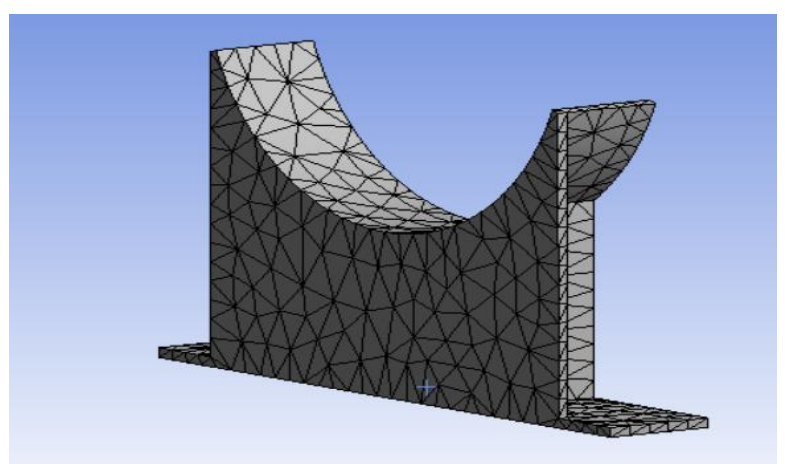

Fig.2.3: Mesh Model of saddle of design 3 


\section{International Journal of Engineering Applied Sciences and Technology, 2020 \\ Vol. 5, Issue 5, ISSN No. 2455-2143, Pages 78-85 \\ Published Online September 2020 in IJEAST (http://www.ijeast.com)}

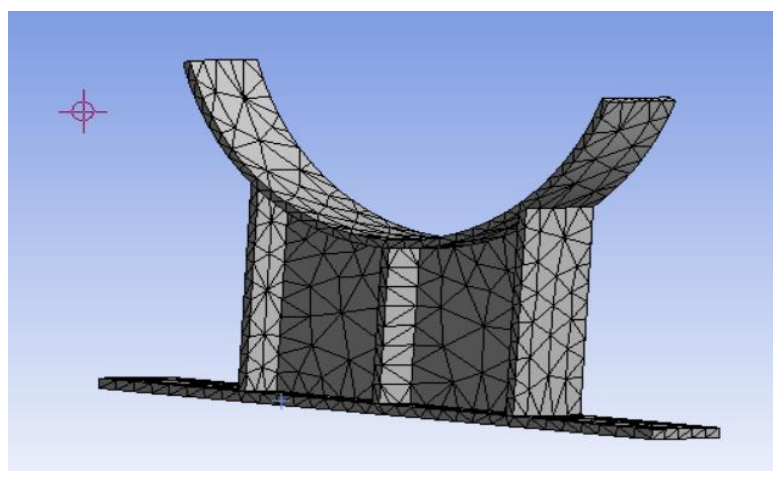

Fig.2.4: Mesh Model of saddle of design 4

\section{BOUNDARY CONDITION}

Boundary Conditions: total load of equipment is applied on the saddle of the top heat exchanger and base plate of saddle supports is fixed in all directions.

\section{Total load on top exchanger}

Operating weight of equipment, $\mathrm{Wo}=65286.5 \mathrm{~N}$

Saddle weight, $\quad \mathrm{Sw}=1626.50 \mathrm{~N}$

Vertical load due to seismic, $\quad$ Vs $=6094.95 \mathrm{~N}$

Total load on top exchanger, $\mathrm{W}=\mathrm{Wo}+\mathrm{Vs}-\mathrm{Sw}$

$$
\begin{aligned}
& \mathrm{W}=65286.5+6094.95-1626.5 \\
& \mathrm{~W}=69754.99 \mathrm{~N}
\end{aligned}
$$

\section{Load per saddle}

Distance between LHS saddle to T.L $=786.5 \mathrm{~mm}$

Load on LHS saddle,

$$
\begin{aligned}
& \mathrm{Q}=(1-\mathrm{aLS} / \mathrm{LS}) * \mathrm{~W}+\max (\text { transverse, longitudinal }) \\
& \mathrm{Q}=(1-786.5 / 1850) * 69754.99+\max (9142.9,4571.7) \\
& \mathrm{Q}=49242.6 \mathrm{~N}
\end{aligned}
$$

Load on RHS saddle,

$Q=$ Total load - load on LHS saddle $+\max$ (transverse, longitudinal)

$Q=69754.99-40099.69+\max (9142.9,4571.7)$

$\mathrm{Q}=39798.2 \mathrm{~N}$

\section{RESULTS AND DISCUSSION}

We have checked the result of designs models of design 1 to design 4 their FEA results with von-miss stress in the top heat exchanger saddle. The details are shown in the figures from Fig 4.1 to Fig 4.8.

\section{For LHS saddle}

Boundary condition for FEA analysis of LHS saddle is as per discussed above i.e. load on LHS saddle is $49242.6 \mathrm{~N}$ and baseplate is fixed.

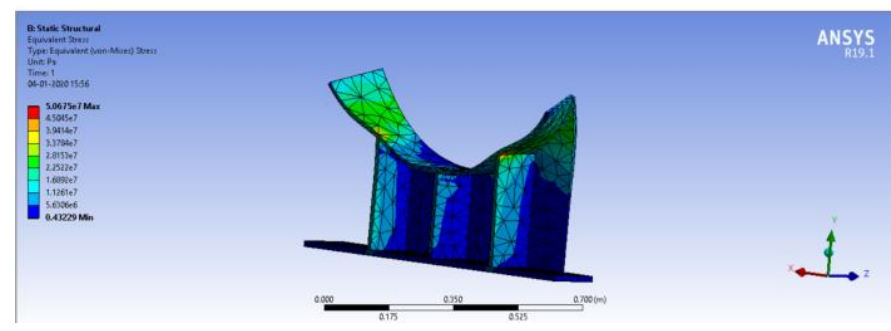

Fig.4.1- Static Structural Analysis of Design 1 Model Color Code shows Von-misses stresses over Saddle Support

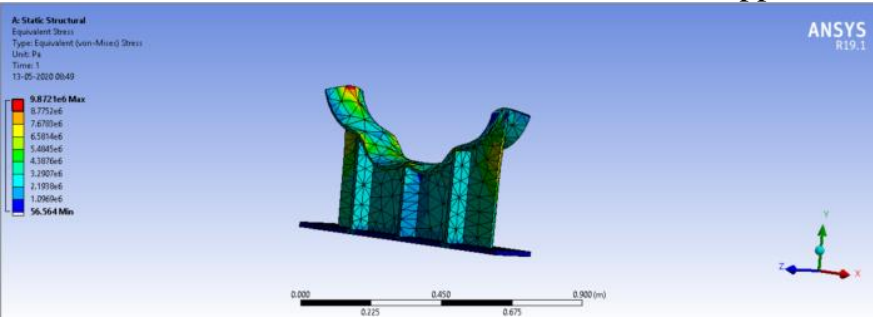

Fig.4.2- Static Structural Analysis of Design 2 Model Color

Code shows Von-misses stresses over Saddle Support

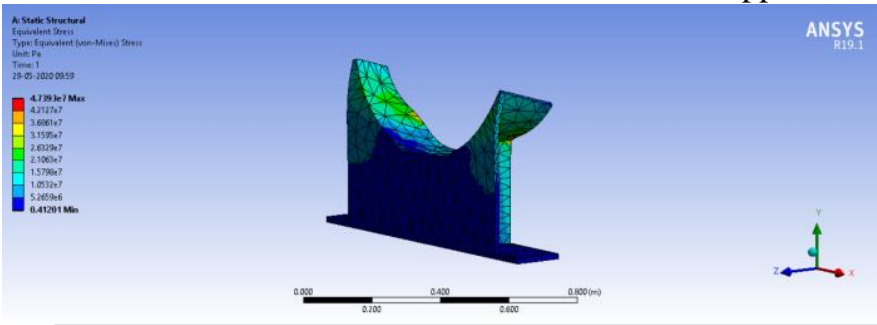

Fig.4.3- Static Structural Analysis of Design 3 Model Color Code shows Von-misses stresses over Saddle Support

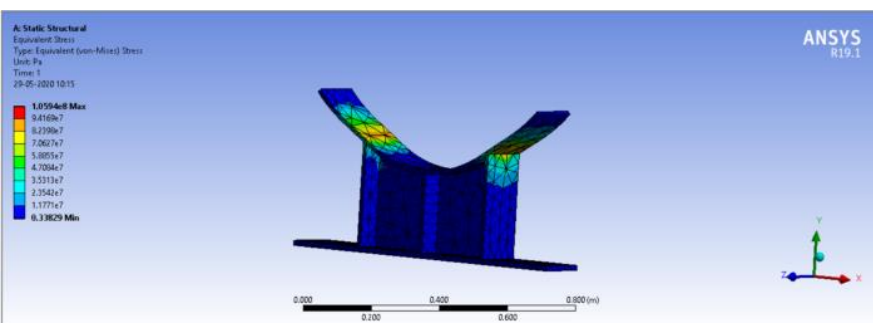

Fig.4.4- Static Structural Analysis of Design 4 Model Color Code shows Von-misses stresses over Saddle Support

\section{For RHS saddle}

Boundary condition for FEA analysis of RHS saddle is as per discussed above i.e. load on RHS saddle is $39798.2 \mathrm{~N}$ and baseplate is fixed. 


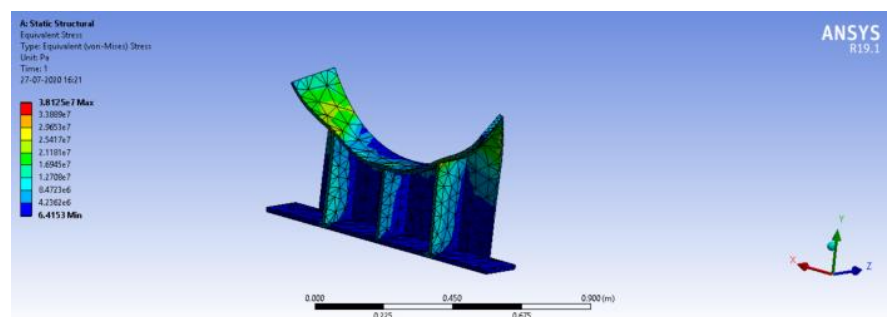

Fig.4.5- Static Structural Analysis of Design 1 Model Color Code shows Von-misses stresses over Saddle Support

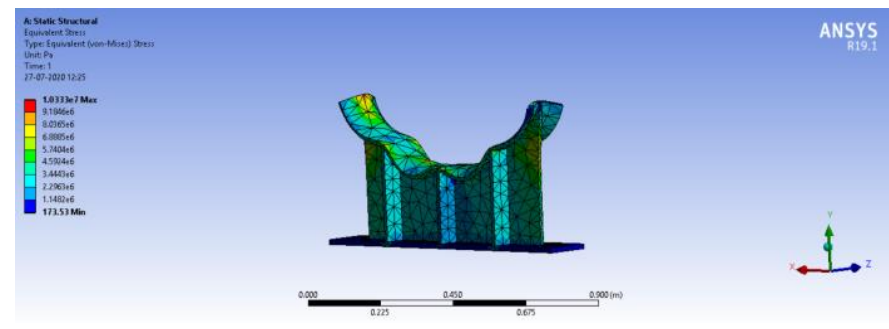

Fig.4.6- Static Structural Analysis of Design 2 Model Color Code shows Von-misses stresses over Saddle Support

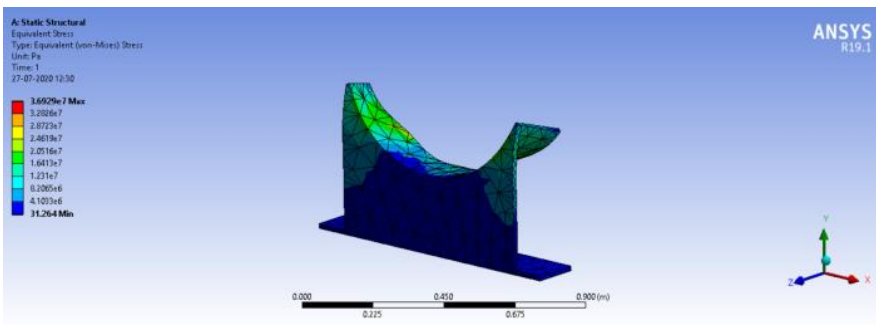

Fig.4.7- Static Structural Analysis of Design 3 Model Color Code shows Von-misses stresses over Saddle Support

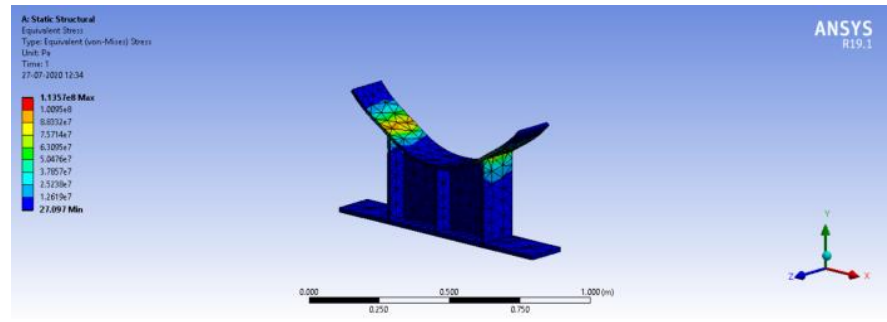

Fig.4.8- Static Structural Analysis of Design 4 Model Color Code shows Von-misses stresses over Saddle Support

\begin{tabular}{|c|c|c|}
\hline & $\begin{array}{c}\text { LHS Saddle } \\
\left(\mathrm{N} / \mathrm{mm}^{2}\right)\end{array}$ & $\begin{array}{c}\text { RHS Saddle } \\
\left(\mathrm{N} / \mathrm{mm}^{2}\right)\end{array}$ \\
\hline Design Model 1 & 50.67 & 38.12 \\
\hline Design Model 2 & 9.87 & 10.33 \\
\hline
\end{tabular}

\begin{tabular}{|c|c|c|}
\hline Design Model 3 & $\mathbf{5 0 . 6 7}$ & $\mathbf{3 8 . 1 2}$ \\
\hline Design Model 4 & $\mathbf{1 0 5 . 9 4}$ & $\mathbf{1 1 3 . 5 7}$ \\
\hline \multicolumn{3}{|c|}{ Table -1 Stress Result } \\
\hline
\end{tabular}

Table 1 indicates the stress intensities of the LHS and RHS saddle of all four design models. According to the FEA analysis all four design models are safe means the stresses in the saddle are below the allowable stress value. From all the four design models, design model 2 which is web plate with center location has a minimum stress intensity.

\section{b) Collection of different design models of bottom exchanger supports}

\section{Saddle models for bottom exchanger}

The different design model collections of saddle for top exchanger using CATIA are,

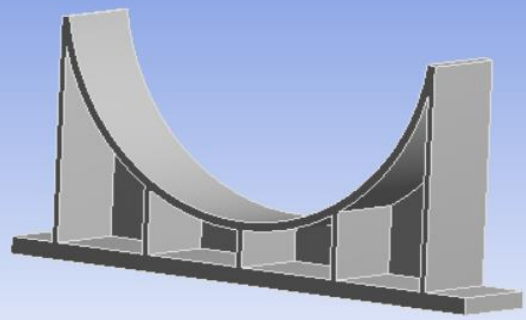

Fig.1.1: Shows Design collection of saddle with five ribs and web plate with rear side location. The ribs are placed at a particular distance from the middle rib plate

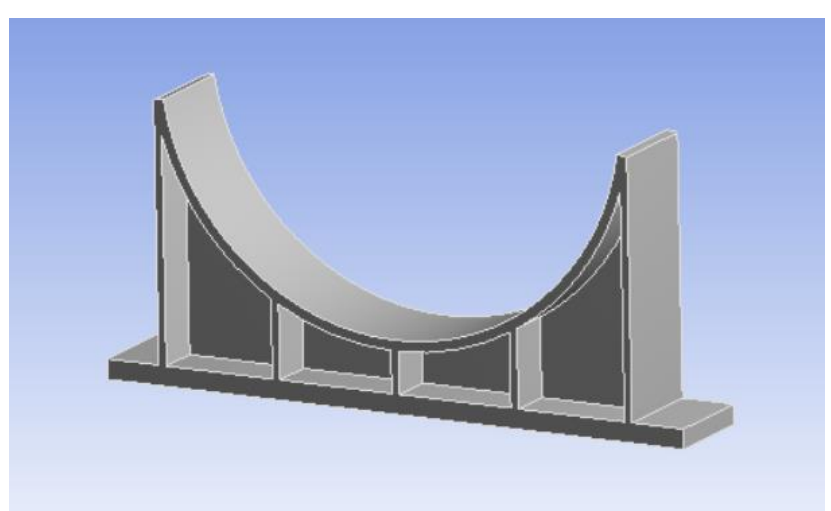

Fig.1.2: Shows Design collection of saddle with five ribs and web plate with center location. The ribs are placed at a particular distance from the middle rib plate 


\section{International Journal of Engineering Applied Sciences and Technology, 2020 \\ Vol. 5, Issue 5, ISSN No. 2455-2143, Pages 78-85 \\ Published Online September 2020 in IJEAST (http://www.ijeast.com)}

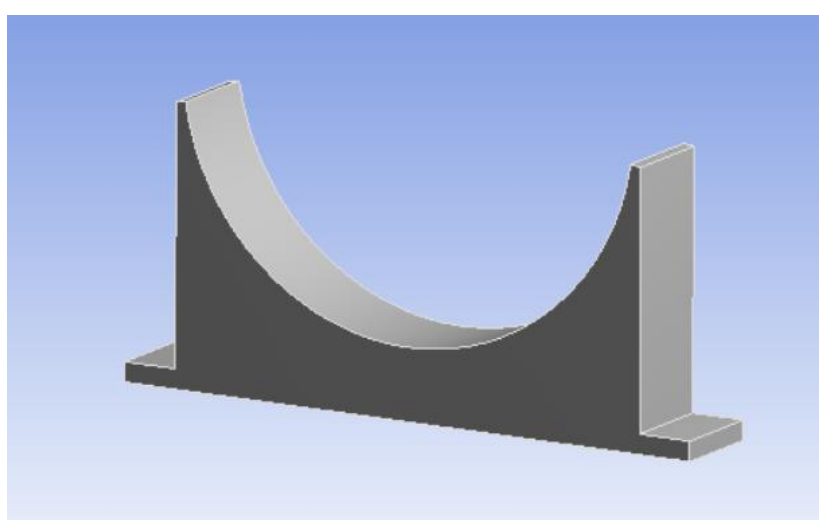

Fig.1.3: Shows Design collection of saddle with five ribs and web plate with front side location. The ribs are placed at a particular distance from the middle rib plate

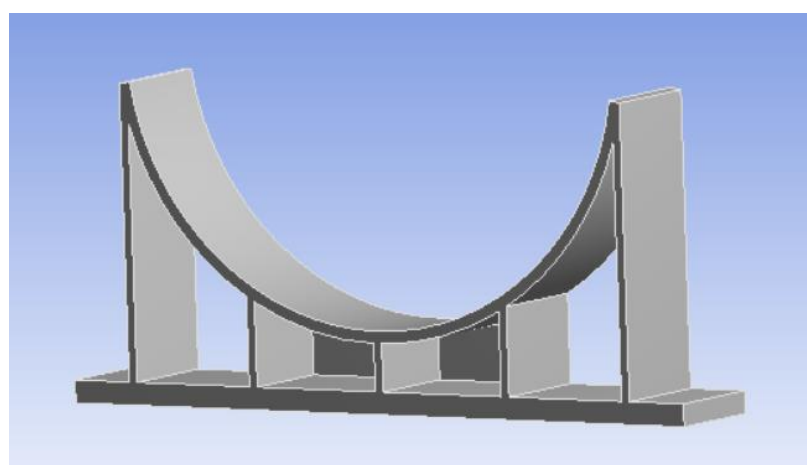

Fig.1.4: Shows Design collection of saddle with five ribs and web plate with center location and between three ribs only. The ribs are placed at a particular distance from the middle rib plate

\section{2. $\quad$ FEA mesh model's}

The following Fig.3.5 to Fig.3.8 shows various design model collection of saddle i.e. Design 1 to Design 4 model meshing,

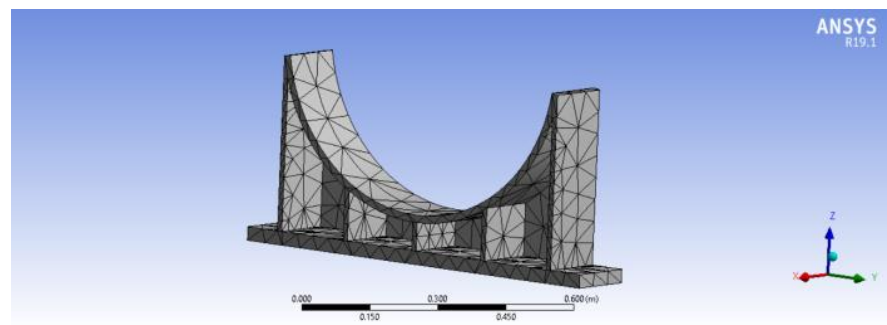

Fig.2.1: Mesh Model of saddle of design 1

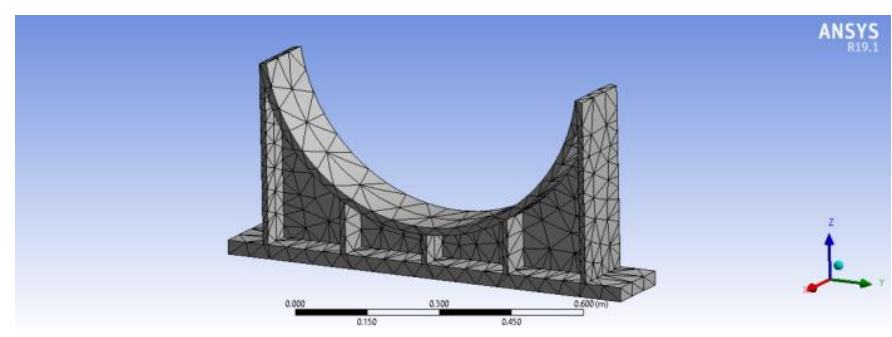

Fig.2.2: Mesh Model of saddle of design 2

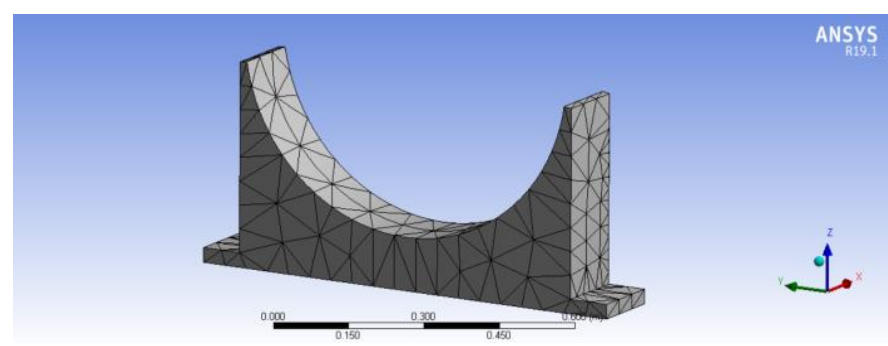

Fig.2.3: Mesh Model of saddle of design 3

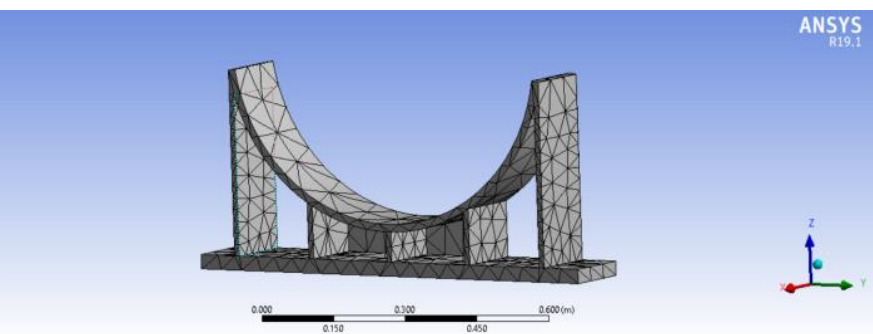

Fig.2.4: Mesh Model of saddle of design 4

\section{Boundary condition}

Boundary Conditions: total load of equipment is applied on the saddle of the bottom heat exchanger and base plate of saddle supports is fixed in all directions.

\section{Total load on bottom exchanger}

Operating weight of equipment, $\mathrm{Wo}=64834.3 \mathrm{~N}$

Total weight of upper shell $=73007.00 \mathrm{~N}$

Total weight of equipment (with upper shell), Wo $=137841.3 \mathrm{~N}$

Saddle weight, $\mathrm{Sw}=1692.25 \mathrm{~N}$

Vertical load due to seismic, Vs $=6052.77 \mathrm{~N}$

Total load on bottom exchanger,

$$
\begin{aligned}
& \mathrm{W}=\mathrm{Wo}+\mathrm{Vs}-\mathrm{Sw} \\
& \mathrm{W}=137841.29+6052.77-1692.25 \\
& \mathrm{~W}=142201.041 \mathrm{~N}
\end{aligned}
$$

\section{Load per saddle}

Distance between LHS saddle to T.L $=786.5 \mathrm{~mm}$

Load on LHS saddle, 
$\mathrm{Q}=(1-\mathrm{aLS} / \mathrm{LS}) * \mathrm{~W}+\max$ (transverse, longitudinal)

$\mathrm{Q}=(1-786.5 / 1850) * 142201.041+\max (9076.8+16883.66,4538.4+33737.33)$

$\mathrm{Q}=120022.11 \mathrm{~N}$

Load on RHS saddle,

$\mathrm{Q}=$ Total load - load on LHS saddle $+\max$ (transverse, longitudinal)

$Q=142201.04-81746.4+\max (9076.08+16883.66,4538.4+33737.3)$

$Q=98731.13 \mathrm{~N}$

\section{RESULTS AND DISCUSSION}

We have checked the result of designs models of design 1 to design 4 their FEA results with von-miss stress in the bottom heat exchanger saddle. The details are shown in the figures from Fig 4.1 to Fig 4.8 .

\section{For LHS saddle}

Boundary condition for FEA analysis of LHS saddle is as per discussed above i.e. load on LHS saddle is $120022.11 \mathrm{~N}$ and baseplate is fixed.

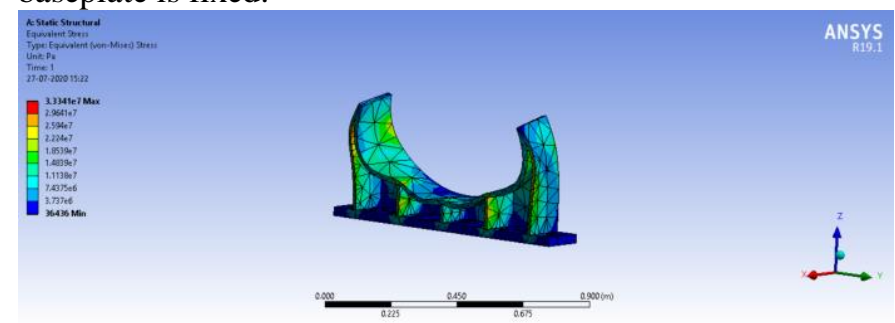

Fig.4.1- Static Structural Analysis of Design 1 Model Color Code shows Von-misses stresses over Saddle Support

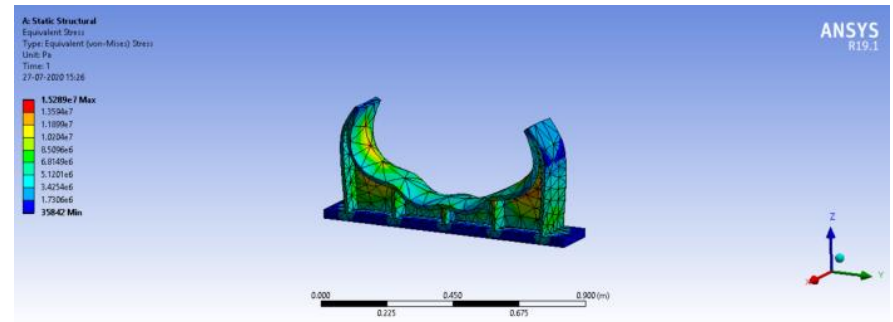

Fig.4.2- Static Structural Analysis of Design 2 Model Color Code shows Von-misses stresses over Saddle Support

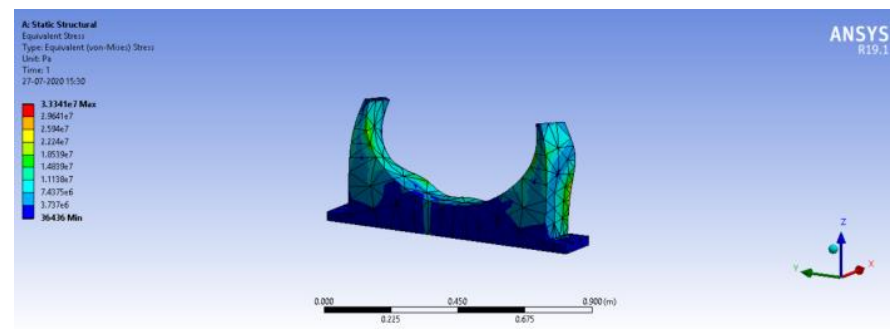

Fig.4.3- Static Structural Analysis of Design 3 Model Color Code shows Von-misses stresses over Saddle Support

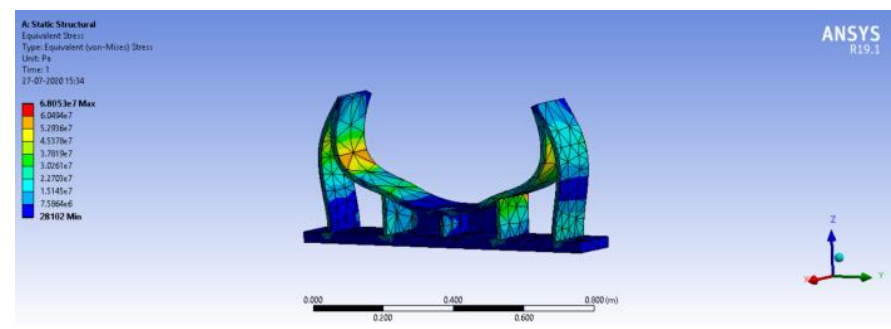

Fig.4.4- Static Structural Analysis of Design 4 Model Color Code shows Von-misses stresses over Saddle Support

\section{For RHS saddle}

Boundary condition for FEA analysis of RHS saddle is as per discussed above i.e. load on RHS saddle is $98731.13 \mathrm{~N}$ and baseplate is fixed.

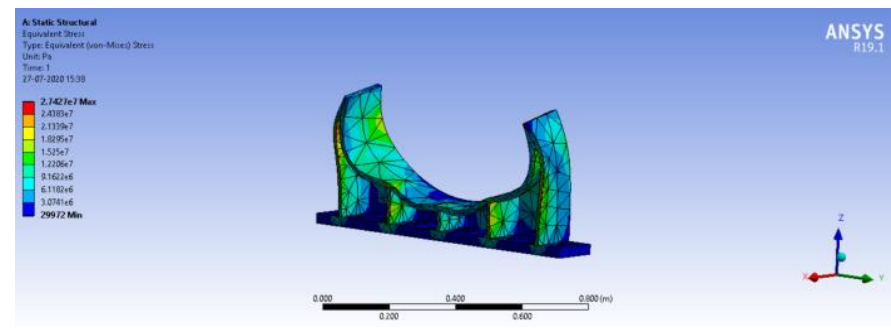

Fig.4.5- Static Structural Analysis of Design 1 Model Color Code shows Von-misses stresses over Saddle Support

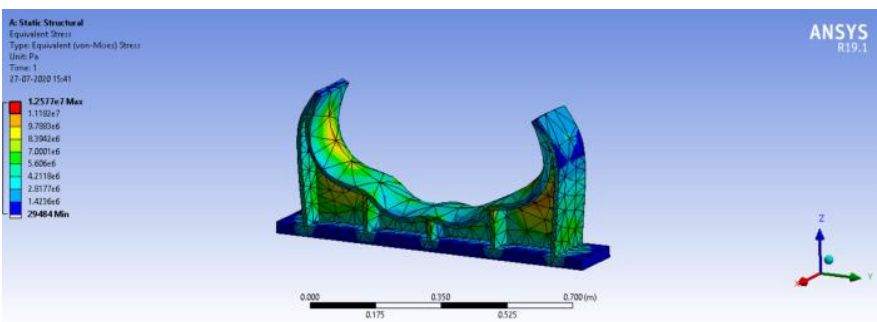

Fig.4.6- Static Structural Analysis of Design 2 Model Color Code shows Von-misses stresses over Saddle Support

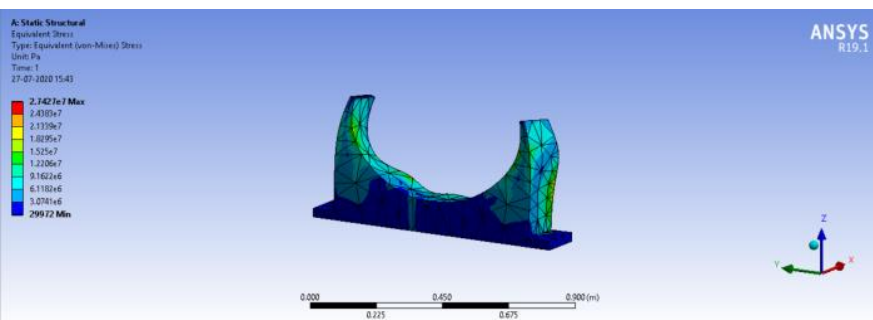

Fig.4.7- Static Structural Analysis of Design 3 Model Color Code shows Von-misses stresses over Saddle Support 


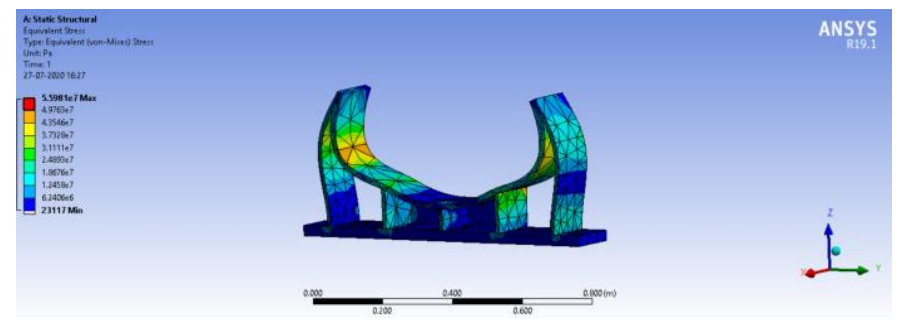

Fig.4.8- Static Structural Analysis of Design 4 Model Color Code shows Von-misses stresses over Saddle Support

\begin{tabular}{|c|c|c|}
\hline & $\begin{array}{c}\text { LHS Saddle } \\
\left(\mathrm{N} / \mathrm{mm}^{2}\right)\end{array}$ & $\begin{array}{c}\text { RHS Saddle } \\
\left(\mathrm{N} / \mathrm{mm}^{2}\right)\end{array}$ \\
\hline Design Model 1 & 33.34 & 27.42 \\
\hline Design Model 2 & 15.28 & 12.57 \\
\hline Design Model 3 & 33.34 & 27.42 \\
\hline Design Model 4 & 68.05 & 55.98 \\
\hline
\end{tabular}

Table -2 Stress Result

Table 2 indicates the stress intensities of the LHS and RHS saddle of all four design models. According to the FEA analysis all four design models are safe means the stresses in the saddle are below the allowable stress value. From all the four design models, design model 2 which is web plate with center location has a minimum stress intensity.

\section{CONCLUSION}

According to the FEA results of design 1, 2, 3 and 4 it is concluded that the stress value over all saddle support is under the yield limit, so every design model of saddle supports will sustain the heat exchanger load but the design model 2 for the saddle support has minimum stress intensity to the applied load. Hence saddle with web plate center location is most optimal and suitable design.

\section{ACKNOWLEDGMENT}

We would like to thank the researchers as well as publishers for making their resources available and teachers for their guidance. We are also thankful to reviewer for their valuable suggestions. We also thank the college authorities for providing the required infrastructure and support. Finally, we would like to extend a heartfelt gratitude to friends and family members.

\section{REFERENCE}

[1] Patil Rohan Balasaheb and Dr. Kulkarni V.V. (2018). Finite Element Analysis of Support Designs for Road Tankers, International Research Journal of Engineering and Technology (IRJET), Vol. 05, Issue 02, p-IISN: 23950072.

[2] M. Aditya, Mr. Patnaik M.M. (2013). Finite Element Analysis of Horizontal Reactor Pressure Vessel Supported on Saddles. International Journal of Innovative Research in Science, Engineering and Technology, Vol. 2, Issue 7, ISSN: 2319-8753.

[3] Mr. Zore Amarnath Y. \& Prof. Qaimi Mudassar G. (2015) Design and Optimization of Saddle for Horizontal Pressure Vessel, International Engineering Research Journal (IERJ) Special Issue 2, ISSN 2395-1621.

[4] Joshi Hirenkumar I, Acharya Ghanshyam D (2017) Design of experiment approach for stress assessment in saddle supported pressure vessels, International Journal of Advance Engineering and Research Development Volume 4, Issue 8, p-ISSN (P): 2348-6406.

[5] Agale Chetan M. and Awachat P.N. (2017)Finite Element Analysis of Horizontal Pressure Vessels Saddle International Journal of Innovations in Engineering and Science, Vol. 2, No.2, e-ISSN: 2456-3463.

[6] Vinod Kumar et al. (2014) Design of Saddle Support for Horizontal Pressure Vessel, International Journal of Mechanical and Mechatronics Engineering, Vol: 8, No: 12.

[7] Gedam Apsara C. and Dr. Bhope D. V. (2015) Stress Analysis of Pressure Vessel with Different End Connections, International Journal of Mechanical Engineering (IIJME), Volume 3, Issue 11, ISSN 23216441.

[8] Anandhu P D, Avis A (2017) Design and Analysis of Horizontal Pressure Vessel and Thickness optimization, International Journal of Innovative Research in Science, Engineering and Technology, Vol. 6, Issue 5, ISSN : 23476710 .

[9] K. Magnucki, P. Stasiewicz, W. Szyc (2003) Flexible saddle support of a horizontal cylindrical pressure vessel", International Journal of Pressure Vessels and Piping 80,pp205-210.

[10] Bichkar Pranita et al. (2018) Study of Shell and Tube Heat Exchanger with the Effect of Types of Baffles, 2nd International Conference on Materials Manufacturing and Design Engineering, 20, pp- 195-200.

[11] Bharathi M. Mani et al. (2017) Design and Fabrication of Shell and Tube Heat Exchanger, International Journal of Latest Engineering Research and Applications (IJLERA) ISSN: 2455-7137, Volume - 02, Issue - 04.

[12] Diamanti Kalliopi et al. (2011) SEISMIC ANALYSIS AND DESIGN OF INDUSTRIAL PRESSURE 
VESSELS, III ECCOMAS Thematic Conference on Computational Methods in Structural Dynamics and Earthquake Engineering.

[13] Tandel Nitant M. and Parmar Jigneshkumar M. (2013) A Review on Pressure Vessel Design and Analysis, 2nd International journal of research, Volume : 3 | Issue : 4 | ISSN - 2250-1991.

[14] Joshi Hirenkumar I, Acharya Ghanshyam D (2017) Study Of The Effect Of Various Factors On The Stress Generation Of Large Horizontal Pressure Vessel By Taguchi Approach., International Journal of Advance Engineering and Research Development Volume Volume 4, Issue 9, , p-ISSN (P): 2348-6406.

[15] American Society of Mechanical Engineers (ASME) (2017), "Boiler and Pressure Vessel Code.

[16] "Pressure Vessel Design Manual" by Dennis Moss and Michael Basic, Fourth Edition. 